\title{
Fiber-Optic Interferometric Sensor for Dynamic Impact Measurement of Transport Trucks
}

\author{
Martin Stolarik ${ }^{1, a}$, and Jan Nedoma ${ }^{2, b^{*}}$ \\ ${ }^{1}$ Department of Geotechnics and Underground Engineering, VSB - Technical University of Ostrava, \\ Faculty of Civil Engineering, Ludvika Podeste 1875/17, 70833 Ostrava-Poruba, Czech Republic \\ ${ }^{2}$ Department of Telecommunications, Faculty of Electrical Engineering and Computer Science, \\ VSB - Technical University of Ostrava, 17. listopadu 15, 70833 Ostrava-Poruba, Czech Republic \\ amartin.stolarik@vsb.cz, bjan.nedoma@vsb.cz
}

\begin{abstract}
Keywords: Ground vibrations, Dynamic response, Truck transport, Fiber-optic interferometric sensor.
\end{abstract}

\begin{abstract}
Ground vibrations are commonly observed by using a standard seismic station equipped with speed seismometers or acceleration seismometers. The seismometers include three mechanical vibrating systems (sensors) and the primary output is the wave pattern of recording velocity or acceleration of the material point oscillation. An alternative new method how it is possible to realize seismic measurements is using of the fiber-optic interferometric sensors. These interferometers are well-known for their ability to make high-precision measurements of optical path difference or changes that may be induced by a refractive index change in the interferometer or a physical displacement. The paper presents a comparison of the results of the standard seismic measurement by using seismic station and of the fiber-optic interferometric sensor. As a source of dynamic load, truck transport was chosen. When trucks passing through unevenness on the road (due to the road damage, the transition area of the bridge etc.), it generates vibrations that are transmitted to the subsoil and can adversely affect the surrounding building objects. Data comparison of the subsoil dynamic response obtained during both approaches of measurements is present in the amplitude and primary in the frequency domain.
\end{abstract}

\section{Introduction}

The vibrations caused by passing wheeled transport [1-3] are also included in the large group of vibrations caused by human activity [4], which are generally called ground vibrations [5]. These vibrations are mainly caused by road irregularities where the main factors are the mass and speed of passing vehicles [6-9]. In general, these vibrations, transmitted from the source of the dynamic load through the rock environment and the base joint to the base structure and from it to the upper structure, must be considered as a negative effect of the seismic load on damage, stability and service life [10]. Being a typical truck traffic transit country is also the Czech Republic where especially heavy freight transport causes a significant dynamic load in areas adjacent to roads that adversely affects constructions and buildings, the inhabitants living in these buildings and the technologies placed therein, which could be very sensitive to such vibrations. The dynamic response of these constructions and buildings as well as of rock formations is commonly monitored using standard seismic stations which have a very wide application in geotechnical engineering and monitoring underground and on the surface [11-16]. The main task of these seismic measurements is to determine the maximum vibration velocities or acceleration, waveform parameters and the frequency spectrum of the measured signals. The data thus obtained serves primarily as input for civil engineers, based on which they can establish and specify influences on the existing technical condition of constructions, their possible susceptibility to damage followed by recommendations of appropriate measures against vibrations where required [17-19].

A new alternative method for taking seismic measurements is the use of interferometric fiberoptic sensors with a high added value [20]. The main advantages over conventional sensors include very small dimensions, electromagnetic field and corrosion resistance, distributed or quasi- 
distributed measurement approach and long service life. Another fundamental difference between a standard seismic station and an alternative in the form of an optical interferometer is definitely the price of a device that is at least one order of magnitude higher for seismic stations. In general, the basic monitored parameter in this alternative approach is a very wide spectrum frequency [21], whereas in the case of standard seismic stations we are often limited by the relatively narrow frequency range of the sensors. Generally, measurement equipment with the optic fibers has wide use in all the technical fields and science disciplines, but for the measurement of the vibrations especially ground vibrations are used rarely only. For example, the possibility to register natural earthquakes is verified experimentally using optic cable [22], which was installed earlier, or special equipment, which works on the principle of optical fibers for the detection of earthquakes, is developed and the results are compared with data extracted by conventional measurements using geophones in laboratory and in-situ [23-24]. Fiber optic interferometric accelerometers were successfully used as part of the distributed measurement system in the underground coal mine, where methane gas and coal combustion as two major hazards were primary observed and interferometric accelerometers monitored coal mine dynamic hazards and coal mine micro-seismic events.

There are not many publications that describe the use of fiber-optic technology for traffic applications. Among the most interesting studies is the one [25], where the authors presented results from a fiber-optic interferometer to detect trains in the Prague subway system. The measuring arm of the interferometer was glued on the glasses plate, the authors state that the sensor is more sensitive. The publication [26-27] described the use of three-armed Mach-Zehnder interferometer for rail transport as a traffic density detector. The proposed system consists of one or more passive fiber trackside sensors and an x 86 processing unit located at the work site. A study of [28] described the used of fiber-optic Michelson interferometer. The authors analyzed the data recorded simultaneously by a fiber-optic interferometer and conventional three-component accelerometers. Article [29] brings results of an acoustic fiber-optic sensor for monitoring of the railway infrastructure from a long distance on the basis of an interferometric connection. The article [30] focused on the use of a fiber-optic interferometer for the perimetric applications. Authors proposed a sensor based on the Mach-Zehnder interferometer to detect vibration response caused by humans moving around the sensor. The authors described the possible use of this sensor to monitor traffic density, but this fact was not tested.

Interesting results are presented in the article [31] where the authors used the interferometric sensor for road vehicle information such as speed and vehicle type. Optical fiber was fixed on the road surface to be used as the sensing media. To increase the sensitivity of such a sensor, an optical Fabry-Perot (F-P) fiber interference was used.

Unlike the above-presented results, in our paper we present original comparison results of the standard seismic station and of the low-cost variation of fiber-optic interferometric sensor. The aim of the research was to test whether a fiber-optic interferometer could replace a conventional seismic station for dynamic impact measurement of transport trucks. As a source of dynamic load, truck transport was chosen, because when trucks is passing through unevenness on the road (due to the road damage, the transition area of the bridge etc.), it generates vibrations that are transmitted to the subsoil and can adversely affect the surrounding building objects. Data comparison of the subsoil dynamic response obtained during both approaches of measurements is present in the amplitude and primary in the frequency domain. Benefits of our solution are plenty. For better clarity, we present the parameters of the proposed interferometric sensor and the used seismic station in Table 1. 
Table 1. The parameters comparison of the seismic station and interferometric sensor.

\begin{tabular}{|c|c|c|c|c|c|}
\hline Sensor & $\begin{array}{c}\text { Frequency } \\
\text { range } \\
{[\mathbf{H z}]}\end{array}$ & Recording & Size [mm] & $\begin{array}{c}\text { Weight } \\
{[\mathbf{k g}]}\end{array}$ & $\begin{array}{c}\text { Price in } \\
\text { dollars }\end{array}$ \\
\hline $\begin{array}{c}\text { Gaia2T }+ \\
\text { ViGeo2 }\end{array}$ & $2-200$ & $\begin{array}{c}\text { Switch on } \\
\text { and continual }\end{array}$ & $\begin{array}{c}280 \times 240 \times \\
130+130 \\
\mathrm{x} 110\end{array}$ & $4 \pm 2.75$ & $\begin{array}{c}2500 \text { and } \\
\text { more }\end{array}$ \\
\hline Interferometric & $3-150$ & $\begin{array}{c}\text { Switch on } \\
\text { and continual }\end{array}$ & $300 \times 300 \times 85$ & 1.2 & $400-500$ \\
\hline
\end{tabular}

This innovative method may contribute to measurement of vibrations in the case of dynamic traffic impacts that require monitoring for example in large cities, using a lot of measuring stations and without the need for expensive seismologic equipment (because our sensor uses the G.652.D optical fibers with minimal attenuation $(0.2 \mathrm{~dB} / \mathrm{km})$, which are widely used in current telecommunications systems and can be readily connected to existing dark cables placed around the roads without the need for any additional transducers). The low attenuation of the used G.652.D fibers allows the evaluation unit to be placed several $\mathrm{km}$ from the sensor.

\section{Theoretical Background}

Interferometers are optical devices employing a phenomenon known as interference. The results of this paper are based on two-arm interferometers, which detect the intensity of superpositions of two waves that have traveled different distances and have different phases. The phase shift occurs in the interferometer itself. Three parameters can be detected that affect the optical beam propagating along the optical path, namely a change in the length of the path, a change in the wavelength $\lambda$ and a change in the propagation velocity. If there is a change in some of the mentioned quantities, the wave phase $\phi$ changes. This is, according to the equation, dependent on the length of the $L$ path, the refractive index $n$ and the wavelength $\lambda$.

$$
\phi=2 \pi L \frac{n}{\lambda}=k L n
$$

The variable $\mathrm{k}$ characterizes the magnitude of the wave vector, which is given by the mathematical relationship of $2 \pi / \lambda$. Below are the relevant mathematical relationships that refer to the MachZehnder type interferometer (hereinafter M-Z), which is used as the basis of this article.

The simplified diagram of the fiber-optic Mach-Zehnder interferometer used in this paper is shown in Figure 1. Laser indicates the light source used, the abbreviation PD denotes a photodetector.

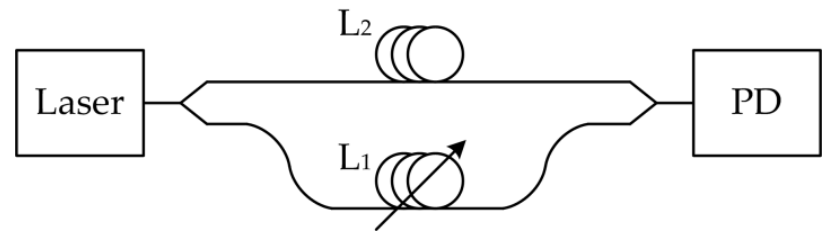

Figure 1. Simplified block diagram of used Mach-Zehnder interferometer, laser and photodetector.

Input intensity of the $M-Z$ type interferometer used is given by the relationship (2) and is transferred to electrical current using the so-called optical sensor (photodetector).

$$
I=2 I_{0}\left\{1+\cos \left[\frac{2 \pi}{\lambda} n\left(L_{1}-L_{2}\right)\right]\right\}
$$

where $L_{1}$ and $L_{2}$ indicate the length of the measuring and reference arm of the interferometer. 
Phase difference between the individual arms of the interferometer is given by the relationship (3):

$$
\phi=\phi_{r}-\phi_{s}=\frac{2 \pi}{\lambda} \delta=\frac{2 \pi}{\lambda} n\left(L_{1}-L_{2}\right)
$$

where $\phi_{r}$ characterizes the arising phase shift in the reference arm and $\phi_{s}$ characterizes the arising phase shift in the measuring arm of the interferometer.

The desired signal (caused by the passing vehicles which produced vibration and acoustic response with low frequencies $\omega$ ) on the output of the photodetector can be expressed by the following equation (4):

$$
i=\varepsilon \cdot I_{0} \cdot \alpha \cdot \cos \left(\phi_{d}+\phi_{s} \cdot \sin \omega t\right)
$$

where $\varepsilon$ is the sensitivity of the photodetector, $\mathrm{I}_{0}$ is the medium signal value, $\alpha$ represents a losses (primary caused by the instability of the light polarization) on the interferometer, $\Phi_{d}$ represents the changing phase shift, $\Phi_{s}$ is the duration of the amplitude, and $\omega$ symbolizes the frequencies applied to the interferometer, i.e. its measurement arm. [32-33]

\subsection{Interferometric sensor unit and data processing}

Figure 2 shows a simplified block diagram of the data processing. A high-pass filter (HP) consist of an RC (resistor-capacity) circuit with a corner frequency of $3 \mathrm{~Hz}$ to filter out the DC (direct current) and low frequencies (temperature influences), an amplifier, and an A/D (Analog/Digital) converter (type NI-USB 6210 measuring device by National Instruments with sampling frequency $5 \mathrm{kS} / \mathrm{s})$.

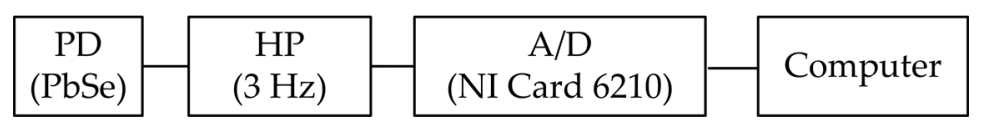

Figure 2. A simplified block diagram of the data processing.

A prototype of the interferometric sensor which was used for the practical measurement is shown in Figure 3. In previous research (please see our articles of our team OPTICE), we tested a methodology for the placement of measuring and reference fibers, also used couplers, attachment and covering materials, optical fiber protections, photodetectors and lasers. The sensor consists of conventional single-mode G.652.D optical fibers (FC/APC connectors) and optical couplers with a coupling ratio of $1: 1$ (tolerance $+/-5 \%$ ). Based on the previously research we used a $\mathrm{PbSe}$ (photoconductive lead selenide photodetector) and laser (DFB type, $1550 \mathrm{~nm}$, spectral line width of $0.03 \mathrm{~nm}$ ) with output power of $3 \mathrm{~mW}$. The analyzed work-frequency characteristic of the interferometric sensor was between the range of 3 to $150 \mathrm{~Hz}$. 


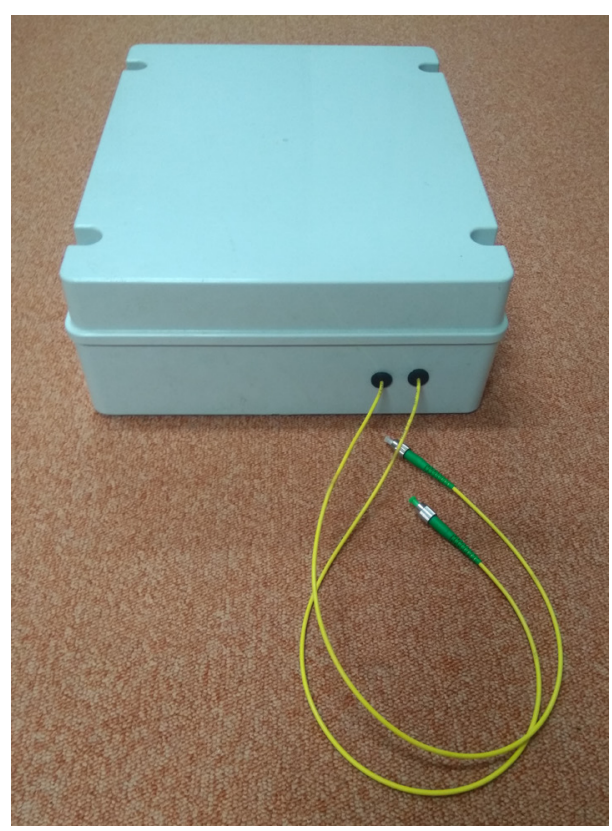

Figure 3. A prototype of the interferometric sensor.

\subsection{Standard seismic station}

The Gaia2T with a ViGeo2 sensor, both produced by the Czech company Vistec Praha, was used for the experiment as a standard seismic station. The Gaia2T is a $138 \mathrm{dBp}-\mathrm{p}$ dynamic range threechannel seismic system with the ability to run both continuous and digital data recording. Time synchronization is provided by the GPS module, and data recording is performed on CompactFlash disks. ViGeo2 is a compact, active, short-period, three-component, speed seismometer for field and stationary use. The seismometer includes three mechanical oscillating systems (sensors) with a frequency of $2 \mathrm{~Hz}$ and a frequency range of $2 \mathrm{~Hz}$ to $200 \mathrm{~Hz}$ (Figure 4).

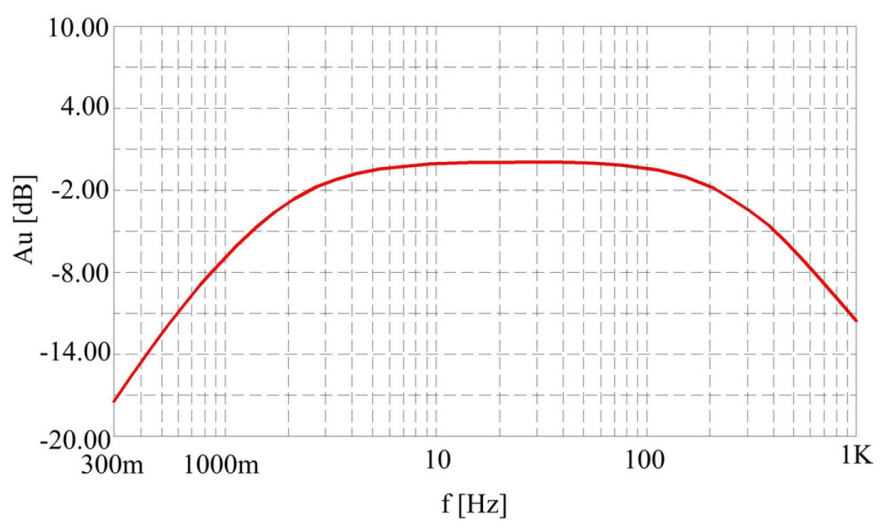

Figure 4. Frequency range of ViGeo2 sensor.

The Seismic Wave Interpretation Program SWIP supplied by Vistec Praha as standard to Gaia devices was used to process seismic data. In this program, the seismic signal can be processed in both the amplitude and the frequency domain (more [34])

\section{Experimental Measurement}

The experimental measurements were taken at the city of Ostrava Svinov Bridges site $(49.8236406 \mathrm{~N}, 18.2138436 \mathrm{E})$. A ViGeo2 speed sensor and the experimental fiber-optic interferometric sensor were installed closely next to each other in the immediate vicinity of the twolane road, just after the road bridge in the so-called transition area of the bridge (Figure 5). A distinct dynamic impact was caused by the passing of the vehicles over the bridge expansion joint, with only the passage of heavy goods vehicles (lorries-without-trailer and lorries-with-trailer) and 
trucks being monitored (Figure 6). Vehicle speeds ranged from 60-70 $\mathrm{km} \cdot \mathrm{h}^{-1}$ (measured with a hand-held Yukon Extend LRS-1000 speedometer). The axial distance from the measuring devices to the nearer lane was $3.4 \mathrm{~m}$. The experimental measurements were taken for four hours.

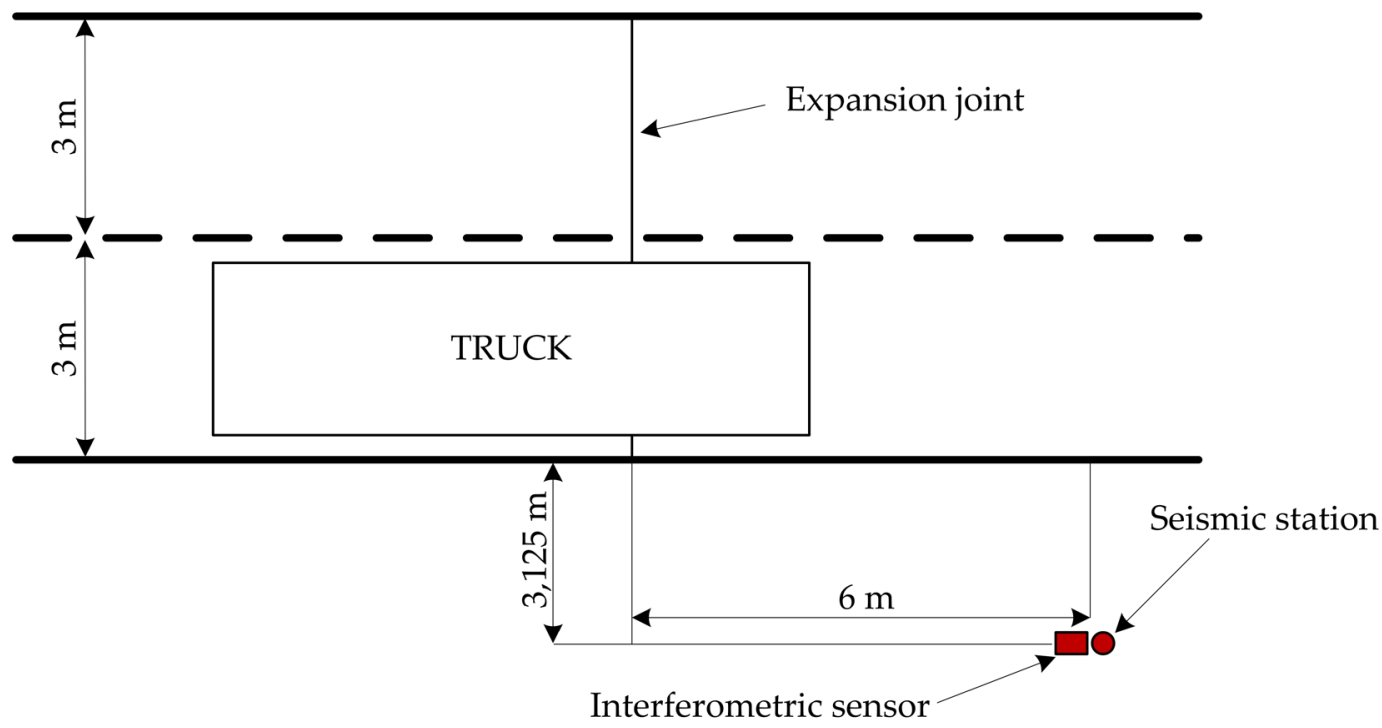

Figure 5. Scheme of the experiment.

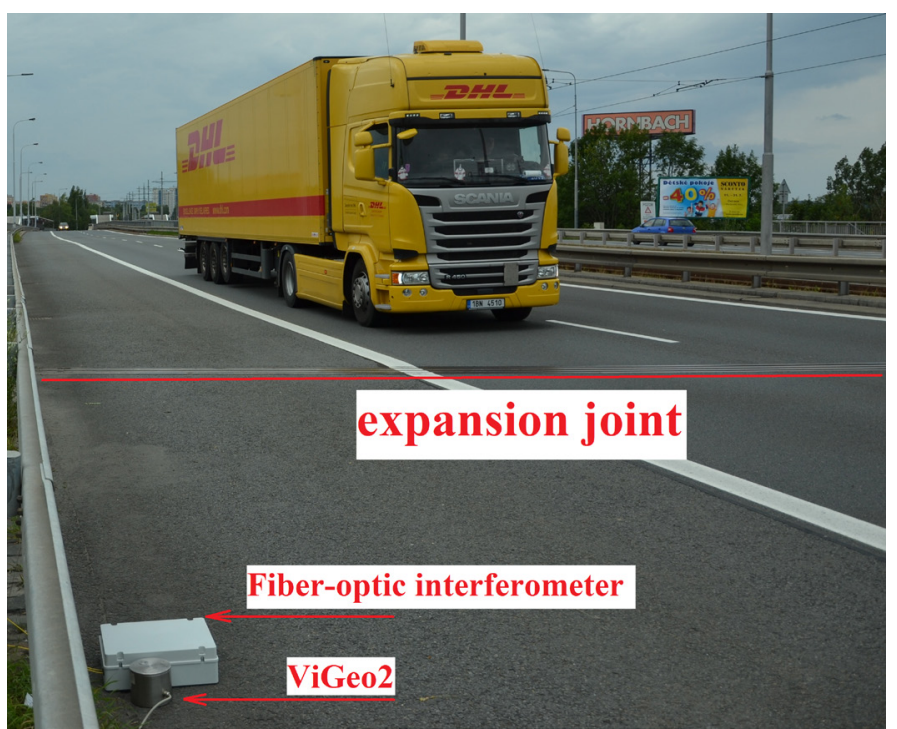

Figure 6. Location of the experiment.

\section{Summary}

The scope of the experiment included the analysis of dozens of passes of heavy goods vehicles or long-distance road vehicles recorded using a standard seismic station and recordings of the interferometric sensor when the experimental interferometric device successfully detected all dynamic responses with $100 \%$ effectiveness.

Figure 7 shows an example representing the truck time-record measured by the interferometric sensor. The time [s] is displayed on the $\mathrm{x}$ axis and the amplitude [V] is displayed on the $\mathrm{y}$ axis, which corresponds to the resulting optical radiation falling on the photodetector and is proportional to the magnitude of the phase changes between the light beams radiating between the measuring and the reference arm of the interferometric sensor. 


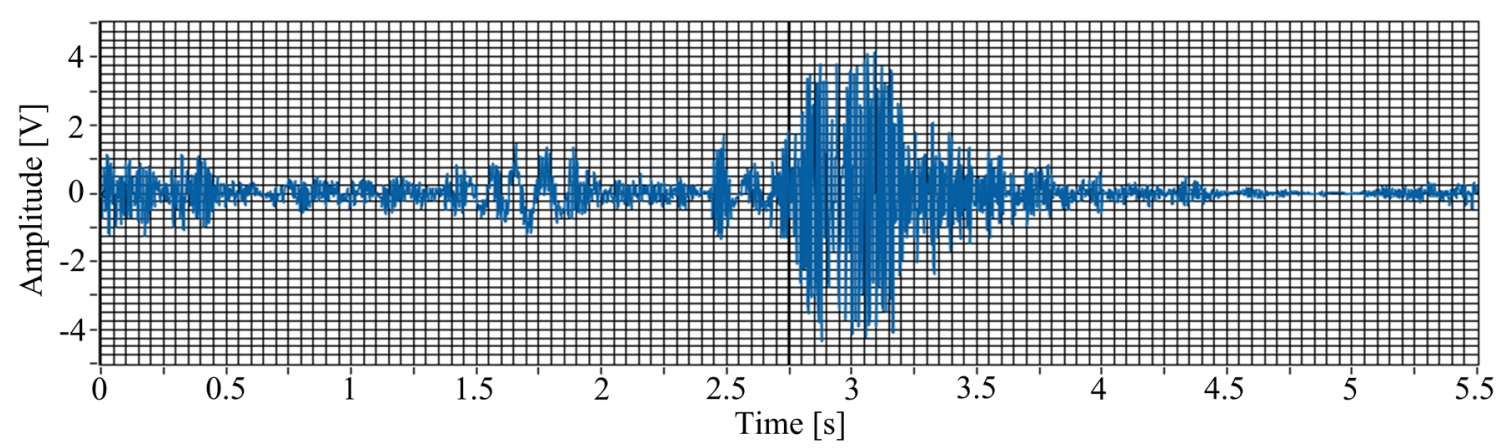

Figure 7. An example representing time-record of the passing truck measured by the interferometric sensor.

Figure 8 shows an example representing the frequency spectrum of the truck passing through the interferometric sensor. The $x$ axis shows the frequency [Hz], and the voltage-amplitude [V] is displayed on the $y$ axis.

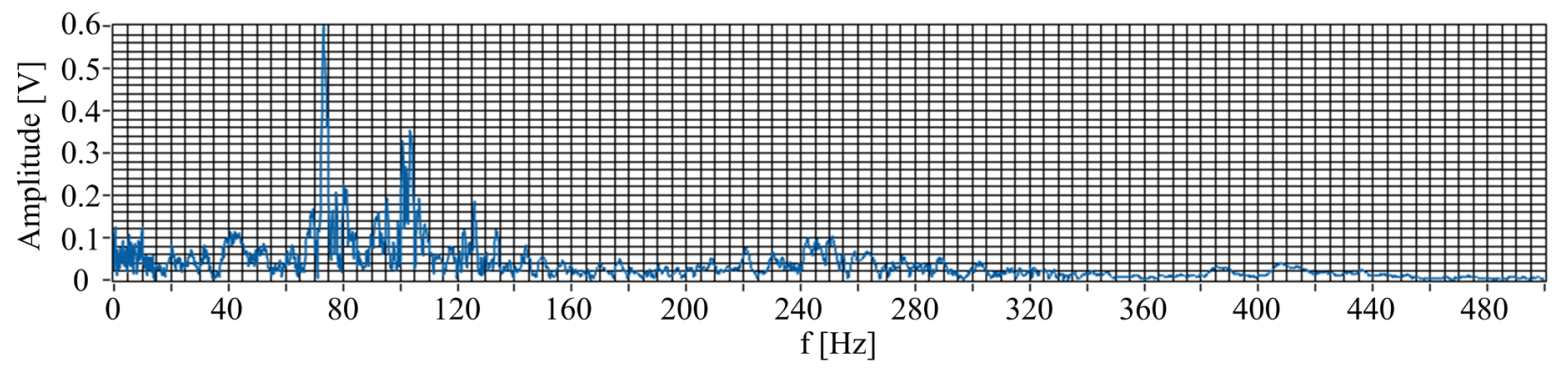

Figure 8. An example representing the frequency spectrum of the truck obtained by the interferometric sensor.

Figure 9 is an example of the truck timing record obtained from Gaia 2T seismic station measurement. On the horizontal axis is the time [s] and on the vertical axis the amplitude [mm.s $\left.{ }^{-1}\right]$. Figure 10 shows the frequency spectrum processed from the time recording obtained on the vertical component. The $x$ axis shows the frequency [Hz] and the amplitude $\left[\mathrm{mm} . \mathrm{s}^{-1}\right]$ is displayed on the $y$ axis.

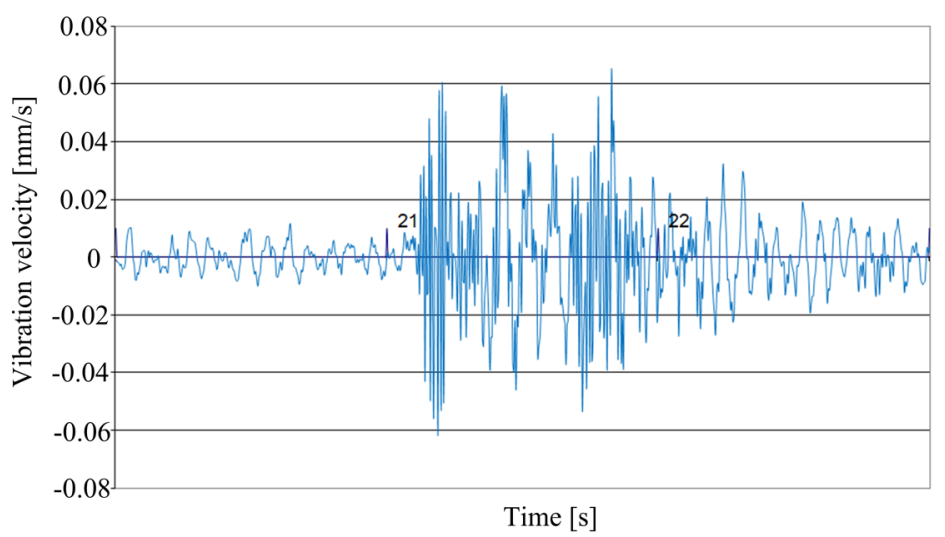

Figure 9. An example representing time record of the passing truck measured by the standard seismic station. 


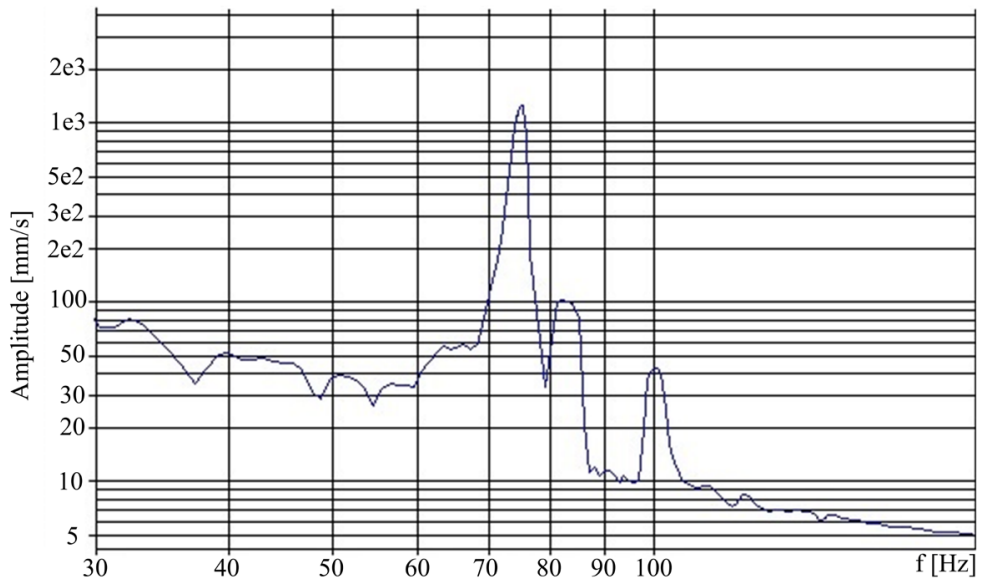

Figure 10. An example representing the frequency spectrum of the truck obtained by the standard seismic station.

As for both the time-records and the frequency spectra, there was a notable coincidence between the measured data by the two measuring devices (standard seismic station and experimental interferometric sensor). The length of time records representing the passage of individual vehicles was always identical and ranged from one to three seconds depending on the type of vehicle $-\mathrm{a}$ lorry-without-trailer, a lorry-with-trailer, or a truck. The maximum positions in the time records also coincided. The character of the frequency spectra did not differ markedly. In general, a frequency range between $60 \mathrm{~Hz}$ and $90 \mathrm{~Hz}$ was always predominant. Multiples of the base frequency then appears at higher frequencies spectra. In all spectra, a distinct peak (maximum) in the range of around $70 \mathrm{~Hz}$ is always clearly identifiable and was the same for all three types of vehicles monitored. The discernible peak in the area of $75 \mathrm{~Hz}$ is a typical manifestation of dynamic effects of heavy cargo traffic, which correlates with the ranges given in ISO 4866:2010 [35]. The same frequencies were independently demonstrated by both the optical interferometer and the seismic station for all recorded vehicles. Table 2, 3 and 4 compares the results of the frequencies received from both devices.

Table 1. Summary of measurement - Truck

\begin{tabular}{|c|cc|cc|}
\hline \multirow{2}{*}{$\begin{array}{c}\text { Time of } \\
\text { phenomenon [s] }\end{array}$} & \multicolumn{2}{|c|}{ Standard seismic station } & Fiber-optic interferometric sensor \\
\cline { 2 - 5 } & $\begin{array}{c}\text { Bandwidth } \\
{[\mathrm{Hz}]}\end{array}$ & $\begin{array}{c}\text { Maximum peak } \\
{[\mathrm{Hz}]}\end{array}$ & $\begin{array}{c}\text { Bandwidth } \\
{[\mathrm{Hz}]}\end{array}$ & $\begin{array}{c}\text { Maximum peak } \\
{[\mathrm{Hz}]}\end{array}$ \\
\hline 1.3 & $60-90$ & 75 & $60-90$ & 76 \\
1.6 & $60-90$ & 74 & $60-90$ & 75 \\
1.5 & $60-90$ & 75 & $60-90$ & 75 \\
1.3 & $60-90$ & 73 & $60-90$ & 74 \\
1.5 & $60-90$ & 74 & $60-90$ & 76 \\
1.4 & $60-90$ & 75 & $60-90$ & 75 \\
1.6 & $60-90$ & 75 & $60-90$ & 77 \\
1.3 & $60-90$ & 74 & $60-90$ & 75 \\
1.5 & $60-90$ & 75 & $60-90$ & 76 \\
1.4 & $60-90$ & 75 & $60-90$ & 75 \\
1.6 & $60-90$ & 76 & $60-90$ & 77 \\
1.3 & $60-90$ & 73 & $60-90$ & 74 \\
1.4 & $60-90$ & 74 & $60-90$ & 73 \\
1.5 & $60-90$ & 75 & $60-90$ & 76 \\
1.5 & $60-90$ & 74 & $60-90$ & 75 \\
1.3 & $60-90$ & 76 & $60-90$ & 76 \\
1.6 & $60-90$ & 75 & $60-90$ & 76 \\
1.5 & $60-90$ & 76 & $60-90$ & 77 \\
1.4 & $60-90$ & 74 & $60-90$ & 75 \\
1.5 & $60-90$ & 74 & $60-90$ & 74 \\
1.3 & $60-90$ & 73 & $60-90$ & 74
\end{tabular}




\begin{tabular}{|l|ll|ll|}
1.6 & $60-90$ & 75 & $60-90$ & 75 \\
1.3 & $60-90$ & 75 & $60-90$ & 75 \\
1.4 & $60-90$ & 76 & $60-90$ & 76 \\
1.5 & $60-90$ & 74 & $60-90$ & 75 \\
1.3 & $60-90$ & 76 & $60-90$ & 77 \\
1.6 & $60-90$ & 75 & $60-90$ & 75 \\
1.5 & $60-90$ & 74 & $60-90$ & 75 \\
1.4 & $60-90$ & 76 & $60-90$ & 77 \\
1.4 & $60-90$ & 74 & $60-90$ & 75 \\
1.5 & $60-90$ & 76 & $60-90$ & 76 \\
1.5 & $60-90$ & 75 & $60-90$ & 75 \\
1.5 & $60-90$ & 74 & $60-90$ & 75 \\
1.3 & $60-90$ & 75 & $60-90$ & 76 \\
1.6 & $60-90$ & 76 & $60-90$ & 76 \\
1.5 & $60-90$ & 74 & $60-90$ & 75 \\
\hline
\end{tabular}

Table 2. Summary of measurement - Lorry-without-trailer

\begin{tabular}{|c|c|c|c|c|}
\hline \multirow[b]{2}{*}{$\begin{array}{c}\text { Time of } \\
\text { phenomenon [s] }\end{array}$} & \multicolumn{2}{|c|}{ Standard seismic station } & \multicolumn{2}{|c|}{ Fiber-optic interferometric sensor } \\
\hline & $\begin{array}{c}\text { Bandwidth } \\
{[\mathrm{Hz}]}\end{array}$ & $\begin{array}{c}\text { Maximum peak } \\
{[\mathrm{Hz}]}\end{array}$ & $\begin{array}{c}\text { Bandwidth } \\
{[\mathrm{Hz}]}\end{array}$ & $\begin{array}{c}\text { Maximum peak } \\
{[\mathrm{Hz}]}\end{array}$ \\
\hline 1.1 & $60-90$ & 69 & $60-90$ & 72 \\
\hline 1.3 & $60-90$ & 71 & $60-90$ & 71 \\
\hline 1.2 & $60-90$ & 69 & $60-90$ & 69 \\
\hline 1.2 & $60-90$ & 70 & $60-90$ & 70 \\
\hline 1.3 & $60-90$ & 71 & $60-90$ & 72 \\
\hline 1.1 & $60-90$ & 72 & $60-90$ & 73 \\
\hline 1.3 & $60-90$ & 70 & $60-90$ & 70 \\
\hline 1.1 & $60-90$ & 69 & $60-90$ & 71 \\
\hline 1.2 & $60-90$ & 70 & $60-90$ & 72 \\
\hline 1.1 & $60-90$ & 71 & $60-90$ & 70 \\
\hline 1.1 & $60-90$ & 70 & $60-90$ & 71 \\
\hline 1.3 & $60-90$ & 69 & $60-90$ & 71 \\
\hline 1.2 & $60-90$ & 72 & $60-90$ & 72 \\
\hline 1.1 & $60-90$ & 71 & $60-90$ & 73 \\
\hline 1.1 & $60-90$ & 71 & $60-90$ & 72 \\
\hline 1.2 & $60-90$ & 70 & $60-90$ & 73 \\
\hline 1.1 & $60-90$ & 69 & $60-90$ & 71 \\
\hline 1.3 & $60-90$ & 70 & $60-90$ & 72 \\
\hline 1.2 & $60-90$ & 71 & $60-90$ & 73 \\
\hline 1.1 & $60-90$ & 70 & $60-90$ & 71 \\
\hline 1.1 & $60-90$ & 72 & $60-90$ & 72 \\
\hline 1.2 & $60-90$ & 70 & $60-90$ & 71 \\
\hline 1.1 & $60-90$ & 71 & $60-90$ & 73 \\
\hline 1.2 & $60-90$ & 71 & $60-90$ & 72 \\
\hline 1.2 & $60-90$ & 70 & $60-90$ & 70 \\
\hline 1.1 & $60-90$ & 69 & $60-90$ & 72 \\
\hline 1.1 & $60-90$ & 70 & $60-90$ & 72 \\
\hline 1.1 & $60-90$ & 72 & $60-90$ & 73 \\
\hline 1.2 & $60-90$ & 71 & $60-90$ & 71 \\
\hline 1.2 & $60-90$ & 70 & $60-90$ & 72 \\
\hline 1.1 & $60-90$ & 72 & $60-90$ & 72 \\
\hline 1.3 & $60-90$ & 71 & $60-90$ & 73 \\
\hline 1.2 & $60-90$ & 72 & $60-90$ & 72 \\
\hline 1.1 & $60-90$ & 72 & $60-90$ & 73 \\
\hline 1.1 & $60-90$ & 70 & $60-90$ & 72 \\
\hline 1.2 & $60-90$ & 71 & $60-90$ & 73 \\
\hline 1.1 & $60-90$ & 69 & $60-90$ & 71 \\
\hline 1.2 & $60-90$ & 70 & $60-90$ & 72 \\
\hline 1.3 & $60-90$ & 71 & $60-90$ & 72 \\
\hline 1.1 & $60-90$ & 70 & $60-90$ & 73 \\
\hline 1.2 & $60-90$ & 72 & $60-90$ & 72 \\
\hline 1.1 & $60-90$ & 71 & $60-90$ & 72 \\
\hline
\end{tabular}


Table 3. Summary of measurement - Lorry-with-trailer

\begin{tabular}{|c|c|c|c|c|}
\hline \multirow{2}{*}{$\begin{array}{c}\text { Time of } \\
\text { phenomenon [s] }\end{array}$} & \multicolumn{2}{|c|}{ Standard seismic station } & \multicolumn{2}{|c|}{ Fiber-optic interferometric sensor } \\
\cline { 2 - 5 } & $\begin{array}{c}\text { Bandwidth } \\
{[\mathrm{Hz}]}\end{array}$ & $\begin{array}{c}\text { Maximum peak } \\
{[\mathrm{Hz}]}\end{array}$ & $\begin{array}{c}\text { Bandwidth } \\
{[\mathrm{Hz}]}\end{array}$ & $\begin{array}{c}\text { Maximum peak } \\
{[\mathrm{Hz}]}\end{array}$ \\
\hline 2.3 & $60-90$ & 76 & $60-90$ & 77 \\
2.4 & $60-90$ & 75 & $60-90$ & 75 \\
2.3 & $60-90$ & 77 & $60-90$ & 76 \\
2.7 & $60-90$ & 76 & $60-90$ & 77 \\
2.6 & $60-90$ & 77 & $60-90$ & 77 \\
2.5 & $60-90$ & 75 & $60-90$ & 76 \\
2.6 & $60-90$ & 76 & $60-90$ & 77 \\
2.3 & $60-90$ & 75 & $60-90$ & 76 \\
2.4 & $60-90$ & 75 & $60-90$ & 76 \\
2.4 & $60-90$ & 77 & $60-90$ & 77 \\
2.5 & $60-90$ & 76 & $60-90$ & 75 \\
2.6 & $60-90$ & 75 & $60-90$ & 76 \\
2.5 & $60-90$ & 76 & $60-90$ & 77 \\
2.6 & $60-90$ & 76 & $60-90$ & 76 \\
2.7 & $60-90$ & 75 & $60-90$ & 75 \\
2.6 & $60-90$ & 77 & $60-90$ & 77 \\
2.4 & $60-90$ & 75 & $60-90$ & 75 \\
2.5 & $60-90$ & 76 & $60-90$ & 77 \\
2.4 & $60-90$ & 75 & $60-90$ & 76 \\
2.6 & $60-90$ & 75 & $60-90$ & 75 \\
2.5 & $60-90$ & 75 & $60-90$ & 76 \\
2.3 & $60-90$ & 77 & $60-90$ & 77 \\
2.4 & $60-90$ & 76 & $60-90$ & 76 \\
2.6 & $60-90$ & 75 & $60-90$ & 76 \\
2.5 & $60-90$ & 76 & $60-90$ & 77 \\
2.6 & $60-90$ & 75 & $60-90$ & 75 \\
2.4 & $60-90$ & 75 & $60-90$ & 76 \\
\hline
\end{tabular}

\section{Discussion}

The paper presented a comparative seismic measurement of two devices with a completely different construction and measuring principle. Classical instrumentation for seismic measurements is intended for monitoring the manifestations of both the natural seismicity, and the dynamic effects due to anthropogenic sources, especially in accordance with national standards, or the Euro Code [36]. In the case of monitoring of dynamic influences in the form of vibrations on residential buildings and for civic amenities, according to the national standard "ČSN 730040 - Loads of technical structures by technical seismicity", the equipment is mostly monitored for the amplitude of the oscillation velocity, which is compared with the limit values of the effective velocity, an important temporal domain of the signal. In the case of e.g. traffic constructions such as railway and road bridges, according to the national standard "ČSN 736209 - Loading tests of bridges", there are actually required certain frequency values, where the maximum deviations from the natural frequency are monitored. For this reason, the primary research in the presented comparative measurement was focused on detailed analysis of frequency spectra. In the temporal domain only the agreement in the length and character of the record was pointed out. The long-term research under preparation will be focused on a detailed correlation analysis of the amplitude domain.

\section{Conclusion}

The paper describes the original results of experimental seismic measurement of the dynamic response of the bridge transition area. The source of the dynamic load was the passing heavy freight traffic. The aim of the measurement was to verify the applicability of the experimentally developed 
fiber-optic interferometric sensor for measuring this type of dynamic load. To compare the measured results, a standard seismic station equipped with a speed sensor was installed in close proximity to the experimental device. In total, one hundred and five phenomena were evaluated. There were thirty-six trucks passes, forty-two lorries-without-trailer passes, and twenty-seven lorries-with-trailer passes. The amplitude range was consistent both in the length of the individual time records and in the character of the records, always depending on the vehicle type. Longer records were those of the lorries-with-trailer passes. The frequency domain data were evaluated in more detail. Here the frequency bandwidth and maximum peaks were monitored. Bandwidth ranged between $60 \mathrm{~Hz}$ and $90 \mathrm{~Hz}$ for all three types of vehicles monitored and the values obtained were identical for both measuring devices. The maximum peak ranged between $69 \mathrm{~Hz}$ and $77 \mathrm{~Hz}$. The difference between the values obtained from the seismic station and the fiber-optic interferometric sensor was $\pm 3 \mathrm{~Hz}$. The realized experimental measurement has shown that the fiber-optic interferometric sensor is able to register the real values representing the given type of dynamic load and the frequency spectrum and that there is a notable coincidence of these values when compared to the data obtained from the measurements taken by the standard seismic station.

\section{Acknowledgments}

The paper has been funded with support of conceptual development of science, research and innovation in 2018, assigned to VSB-Technical University of Ostrava, The Ministry of Education, Youth and Sports in the Czech Republic. This article was supported by the Ministry of Education of the Czech Republic (Project No. SP2019/67).

\section{References}

[1] M. Crispino, M. D'Apuzzo, Measurement and prediction of traffic-induced vibrations in a heritage building, Journal of Sound and Vibration. 246 (2001) 319-335.

[2] P. Tucholka, K. Kielbasiński, and R. Mieszkowski, Tracing seismic surface waves induced by road traffic in urban environment: example of st. Catherine's church hill in Warsaw, Geologija. (2008) 79-85.

[3] Z. Kaláb, E. Hrubesova, Evaluation of seismic effect of traffic-induced vibrations, Acta Montanistica Slovaca. 20 (2015) 33-37.

[4] R. Sarsby, Environmental Geotechnics. Thomas Telford Limited, London, 2000.

[5] D.-S. Kim, J.-S. Lee, Propagation and attenuation characteristics of various ground vibrations, Soil Dynamics and Earthquake Engineering. 19 (2000) 115-126.

[6] M.A. Lak, G. Degrande, and G. Lombaert, The effect of road unevenness on the dynamic vehicle response and ground-borne vibrations due to road traffic, Soil Dynamics and Earthquake Engineering. 31 (2011) 1357-1377.

[7] G.R. Watts, V.V. Krylov, Ground-borne vibration generated by vehicles crossing road humps and speed control cushions, Applied Acoustics. 59 (2000) 221-236.

[8] M. Picu, L. Picu, Experimental study of road traffic vibrations impact on heritage buildings in Braila, Romania, Springer Proceedings in Physics. 198 (2018) 389-395.

[9] M. Mhanna, M. Sadek, and I. Shahrour, Prediction and mitigate on of traffic induced ground vibrations in an urban zone, WIT Transactions on the Built Environment. 116 (2011) 701-711.

[10]H. Hama, S. Fukada, K. Usui, Y. Kajikawa, and T. Matsuda, Infrasound and ground vibration transmitted from highway bridges using moving trucks, $20^{\text {th }}$ International Congress on Acoustics 2010, ICA 2010 - Incorporating Proceedings of the 2010 Annual Conference of the Australian Acoustical Society. (2010) 1130-1135. 
[11]C. Zou, Y. Wang, J.A. Moore, and M. Sanayei, Train-induced field vibration measurements of ground and over-track buildings, Science of the Total Environment. 575 (2017) 1339-1351.

[12]G. Degrande, L. Schillemans, Free field vibrations during the passage of a thalys high-speed train at variable speed, Journal of Sound and Vibration. 247 (2001) 131-144.

[13]M. Stolarik, M. Pinka, and R. Fojtik, Seismic load due to the jet planes operation, International Multidisciplinary Scientific GeoConference Surveying Geology and Mining Ecology Management, SGEM. (2015) 619-626.

[14]M. Stolarik, M. Pinka, and J. Marsalek, Analysis of load of the tunnel definitive lining due to vibrations of various sources, Advanced Materials Research. 1020 (2014), 429-434.

[15]Z. Kalab, D. Hanslian, M. Stolarik, and M. Pinka, Analysis of wind energy potential and vibrations caused by wind turbine on its basement, Acta Montanistica Slovaca. 19 (2014) 151-159.

[16]M. Stolarik, M. Pinka, Seismic impact of the railway on the geotechnical constructions, IOP Conference Series: Materials Science and Engineering, (2017) 012049.

[17]P. Clemente, D. Rinaldis, Protection of a monumental building against traffic-induced vibrations, Soil Dynamics and Earthquake Engineering. 17 (1998) 289-296.

[18]M. Pinka, M. Stolarik, R. Fojtik, and T. Novotny, Seismic load analysis around the temporary bridge construction before and after vibration mats installation, Advanced Materials Research. 1020 (2014) 441-446.

[19] S. Fukada, K. Usui, T. Yoshimura, T. Okada, H. Hama, and T. Kishi, Effectiveness of dampers in controlling a vibration problem near a highway bridge, Journal of Civil Structural Health Monitoring. 2 (2012) 109-122.

[20]G. Busca, A. Cigada, P. Mazzoleni, and E. Zappa, Vibration Monitoring of Multiple Bridge Points by Means of a Unique Vision-Based Measuring System, Experimental Mechanics. 54 (2014) 255-271.

[21]A. Wada, K. Ikum, S. Tanaka, and N. Takahashi, Experimental investigation of dynamic characterisitics of wavelength of DFB-LD for FBG-FPI vibration sensor based on wavelength-totime mapping, Proceedings of SPIE - The International Society for Optical Engineering, (2012).

[22]P. Jousset, T. Reinsch, T. Ryberg, H. Blanck, A. Clarke, R. Aghayev, G.P. Hersir, J. Henninges, M. Weber, and C.M. Krawczyk, Dynamic strain determination using fibre-optic cables allows imaging of seismological and structural features, Nature Communications. 9 (2018) 2509.

[23]T.-C. Liang, Y.-L. Lin, A fiber-optic sensor for the ground vibration detection, Optics Communications. 306 (2013) 190-197.

[24]T. Liu, Y. Wei, G. Song, B. Hu, L. Li, G. Jin, J. Wang, Y. Li, C. Song, Z. Shi, L. Zhao, J. Hu, W. Zhao, M. Hou, R. Li, and J. Wang, Fibre optic sensors for coal mine hazard detection, Measurement: Journal of the International Measurement Confederation. (2018) 211-223.

[25]Kepak, S., Cubik, J., Zavodny, P., Siska, P., Davidson, A., Glesk, I., Vasinek, V. Fibre optic track vibration monitoring system, Optical and Quantum Electronics. 48 (2016).

[26] Kepak, S., Cubik, J., Zavodny, P., Hejduk, S., Nedoma, J., Davidson, A., Vasinek, V. Fibre optic portable rail vehicle detector. In Proceedings of SPIE. 10142 (2016).

[27] Kepak, S., Cubik, J., Nedoma, J., Hruby, D., Hejduk, S., Zavodny, P., Fajkus, M., Vasinek, V. Compact Fiber Optic Trackside Sensor for Rail Vehicle Detection and Analysis, IFACPapersOnLine. 51 (2018) 220-224. 
[28] Papp, B., Donno, D., Martin, J.E., Hartog, A.H. A study of the geophysical response of distributed fibre optic acoustic sensors through laboratory-scale experiments, Geophysical Prospecting. 65 (2017) 1186-1204.

[29] Udd, E. Fiber optic sensors for infrastructure applications. Oregon State Library. Available online: http://www.oregon.gov/ODOT/TD/TP_RES/ResearchReports/FiberOpticSensors.pdf (accessed on 20 March 2019).

[30] Nedoma, J., Fajkus, M., Martinek, R., Mec, P., Novak, M., Bednarek, L., Vasinek, V. Interferometer for securing entrance areas of buildings, In Proceedings of SPIE. 10440 (2017).

[31] Feng, L.L., Wang, Y.T., Ruan, C., Tao, S. Road vehicle information collection system based on distributed fiber optics sensor, Advanced Materials Research. 1030 (2014) 2105-2109.

[32] Goodwin, E. G., J. C. Wyant (2006). Field guide to interferometric optical testing. Bellingham: SPIE. ISBN 978-081-9465-108.

[33]Born, M., E. Wolf (1999). Principles of optics: electromagnetic theory of propagation, interference and diffraction of light. 7th ed. New York: Cambridge University Press, ISBN 05-2164222-1.

[34]J. Wiszniowski, P. Wiejacz, Program SWIP, Institute of Geophysics, Polish Academy of Sciences, Warszawa, 2003.

[35] BS ISO 4866:2010. Mechanical vibration and shock, vibration of fixed structures, guidelines for the measurement of vibrations and evaluation of their effects on structures, BSI Group (2010).

[36] Czech, K., Gosk, W. Analysis of the Vibration Propagation Induced by Pulling out of Sheet Pile Wall in a Close Neighbourhood of Existing Buildings, Procedia Engineering. 143 (2016) 14601467. 